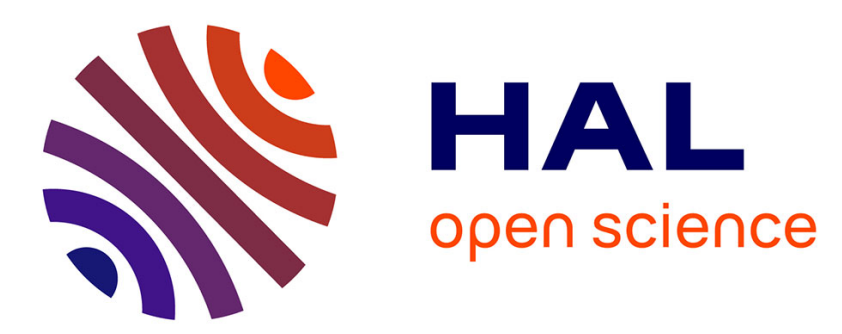

\title{
Multiscale modeling of ovarian follicular development: From follicular morphogenesis to selection for ovulation
}

Danielle Monniaux, Philippe Michel, Marie Postel, Frédérique Clément

\section{To cite this version:}

Danielle Monniaux, Philippe Michel, Marie Postel, Frédérique Clément. Multiscale modeling of ovarian follicular development: From follicular morphogenesis to selection for ovulation. Biology of the Cell, 2016, 108 (6), pp.1-12. 10.1111/boc.201500087 . hal-01294630

\section{HAL Id: hal-01294630 \\ https://hal.inria.fr/hal-01294630}

Submitted on 7 Jun 2016

HAL is a multi-disciplinary open access archive for the deposit and dissemination of scientific research documents, whether they are published or not. The documents may come from teaching and research institutions in France or abroad, or from public or private research centers.
L'archive ouverte pluridisciplinaire HAL, est destinée au dépôt et à la diffusion de documents scientifiques de niveau recherche, publiés ou non, émanant des établissements d'enseignement et de recherche français ou étrangers, des laboratoires publics ou privés. 
Multiscale modeling of ovarian follicular development: from follicular morphogenesis to selection for ovulation

Danielle Monniaux ${ }^{* 1}$, Philippe Michel ${ }^{\dagger}$, Marie Postel $^{\sharp \S}$ and Frédérique Clément ${ }^{\S}$

"INRA, UMR85 Physiologie de la Reproduction et des Comportements, F-37380 Nouzilly, France; CNRS, UMR7247, F-37380 Nouzilly, France; Université François Rabelais de Tours, F-37041 Tours, France; IFCE, F-37380 Nouzilly, France, ${ }^{\dagger}$ Université de Lyon, CNRS, Ecole Centrale de Lyon, Institut Camille Jordan, 69134 Ecully Cedex, France, $\ddagger$ Sorbonne Universités, UPMC Univ Paris 06, CNRS, UMR 7598, Laboratoire Jacques-Louis Lions, F75005, Paris, France, and ${ }^{\S}$ Centre de Recherche Inria de Paris, 2 rue Simone Iff, CS 42112 , 75589 Paris Cedex 12, France.

${ }^{1}$ To whom correspondence should be addressed (email dmonniaux@tours.inra.fr)

Tel: (33) 02474275 10, Fax: (33) 0247427743

Running title: Modeling of ovarian follicular development

Key words: cell cycle, germ cell, ovary, follicle, mathematical model

Edited final version published in: Biol. Cell (2016) 108, 1-12 DOI: 10.1111/boc.201500087

\section{Conflict of interest statement}

The authors have declared no conflict of interest.

Abbreviations used: BMP15: bone morphogenetic protein 15; CYP19A1, cytochrome P450, family 19, subfamily A, polypeptide 1; FSH, follicle-stimulating hormone; GDF9, growth differentiation factor 9; INHA, inhibin, alpha; KIT, v-kit Hardy-Zuckerman 4 feline sarcoma viral oncogene homolog; KITLG, KIT ligand; LH, luteinizing hormone 


\begin{abstract}
In this review, we present multiscale mathematical models of ovarian follicular development that are based on the embedding of physiological mechanisms into the cell scale. During basal follicular development, follicular growth operates through an increase in the oocyte size concomitant with the proliferation of its surrounding granulosa cells. We have developed a spatio-temporal model of follicular morphogenesis explaining how the interactions between the oocyte and granulosa cells need to be properly balanced to shape the follicle. During terminal follicular development, the ovulatory follicle is selected among a cohort of simultaneously growing follicles. To address this process of follicle selection, we have developed a model giving a continuous and deterministic description of follicle development, adapted to high numbers of cells and based on the dynamical and hormonally-regulated repartition of granulosa cells into different cell states, namely proliferation, differentiation and apoptosis. This model takes into account the hormonal feedback loop involving the growing ovarian follicles and the pituitary gland, and enables the exploration of mechanisms regulating the number of ovulations at each ovarian cycle. Both models are useful for addressing ovarian physiopathological situations. Moreover, they can be proposed as generic modeling environments to study various developmental processes and cell interaction mechanisms.
\end{abstract}

\title{
1. Introduction
}

In mammals, the ovarian follicles develop from a reserve of quiescent primordial follicles constituted early in life. During the female life, this ovarian reserve is progressively exhausted by the asynchronous activation of follicles for growth (Gougeon, 1996; McGee and Hsueh, 2000; Monget et al., 2012; Monniaux et al., 2014). Each primordial follicle is composed of a germ cell named oocyte, surrounded by a single layer of about fifteen flattened resting somatic cells named granulosa cells. When a primordial follicle is activated by metabolic or hormonal cues coming from the ovarian cortex, its granulosa cells take a cuboidal shape and activate in turn the awakening of the oocyte; this activation process gives rise to a primary follicle consisting of a growing oocyte surrounded by one layer of proliferating granulosa cells (Zhang et al., 2014). Thereafter, multiple layers of proliferating granulosa cells develop around the oocyte which further enlarges. In the preantral follicle made up of three to six granulosa cell layers, a vascularized theca differentiates around the granulosa tissue. At this stage, small extracellular cavities filled with follicular fluid derived from the thecal vasculature begin to form in the granulosa (Rodgers and Irving-Rodgers, 2010). In the small antral follicle (of 250-300 $\mu \mathrm{m}$ diameter in all mammals), the cavities merge to form a single central cavity named antrum which separates the population of proliferating granulosa cells into two main groups, the cumulus cells associated with the oocyte and the mural granulosa cells lining the follicular wall. Antral follicle growth is characterized by the rapid enlargement of the antrum whereas the mural granulosa cells of the follicle undergo final differentiation, becoming highly estrogenic and LH (luteinizing hormone) responsive, and loose concomitantly their proliferative activity (Monniaux et al., 1997). In the antral follicle, the oocyte, after completing its growth, acquires progressively the competence to resume meiosis and ensure normal development of the embryo after fertilization. The main stages of follicular development are illustrated in Supplementary Figure 1 of Appendix A.

During the so-called basal follicular development, the primary, preantral and small antral follicles are little responsive to the pituitary gonadotropins FSH (follicle-stimulating hormone) and LH. This slow developmental process (which lasts several weeks in rodents and several months in large animals and humans) is controlled by a privileged dialogue between the oocyte and its surrounding granulosa cells. The dialogue operates on the basis of exchanges of small molecules through gap junctions, and the reciprocal action of cytokines and growth factors produced specifically by one of the two cell types (the oocyte or granulosa 


\section{Monniaux et al. 2016 Multiscale modeling of ovarian follicular development}

cell) and acting on the other when present in its vicinity (Kidder and Mhawi, 2002; Otsuka and Shimasaki, 2002; Thomas and Vanderhyden, 2006).

In contrast, the terminal phase of antral follicle development is highly dependent on gonadotropin supply and is achieved in a few days, within an ovarian cycle. It is a high "risk phase" for the growing follicle which can arrest its development and regress by a physiological process named atresia, if the endocrine and paracrine environment is inadequate for the differentiation stage of its granulosa cells. At each ovarian cycle, the number of ovulations is the result of a selection process in a cohort of simultaneously developing follicles, which is finely regulated by endocrine loops between the ovaries and hypothalamopituitary complex (Scaramuzzi et al., 2011).

The granulosa cells are the cellular units orchestrating the development of follicles. During the basal phase of follicular development, their proliferative activity, controlled by tight interactions with the oocyte, drives the growth and shaping of the follicle. In the course of follicular growth, they become gradually more and more responsive to FSH. During the terminal phase of follicular development, the granulosa cells experience a vulnerability phase in which their fate (proliferation, differentiation toward more oestrogenic capacity, or death by apoptosis) is strictly dependent on their FSH environment. This FSH-controlled cell fate will determine the follicle's fate, namely further development toward ovulation or regression by atresia. Putting these observations together, we chose to design modeling approaches centered on the granulosa cell for both the basal and terminal phases of follicular development. These approaches have been developed in sheep, a species of agronomical interest in which data of granulosa cell kinetics, follicular growth (assessed by ovarian ultrasonography scanning) and endocrine time series of FSH and ovarian hormones (estradiol, inhibin) are available. Moreover, in contrast to rodents, this species presents interesting similarities with the human species for the duration of follicular development, the length of ovarian cycle and the numbers of ovulations.

\section{Follicular morphogenesis: an example of interactions between germ and somatic cells}

2.1. Cell-based model of follicular morphogenesis

During basal follicular development up to antrum formation, follicular growth operates through an increase in the oocyte size concomitant with the proliferation of its surrounding granulosa cells. In sheep, the oocyte diameter increases 2.8 -fold, the granulosa cell population doubles some 7-8 times and the number of granulosa cell layers increases from 1 to 6 cell layers before antrum formation (Lundy et al., 1999). The time taken to complete this process varies between 50 and 150 days with very little follicular atresia (Scaramuzzi et al., 2011).

We have developed a spatio-temporal model explaining how the interactions between the oocyte and its surrounding granulosa cells contribute to build a preantral follicle, and giving a description of follicular morphogenesis on a cellular and mechanistic basis (Clément et al., $2013 \mathrm{~b}$ ). As the number of granulosa cells is low (less than twenty cells in primary follicles and about 4000 cells in large preantral follicles), we chose an Individual Based Model giving a stochastic and discrete description of follicle development. Each granulosa cell is an individual represented by its age and location in a three-dimensional space. Granulosa cells are subject to both mitosis and displacement events, but there is neither cell death nor quiescence. The general law of evolution of the cell population operates as a counting process, which registers all the events of cell division and displacement affecting the population of granulosa cells. The model is multiscale in nature since different outputs can be obtained at the individual cell (microscopic) scale (cell location in space, cell age), but also at the semi-local (mesoscopic) scale of cell sub-populations (cell layers and clonal lineages) and 
at the global (macroscopic) scale of the whole follicle (oocyte and follicle diameters, total cell number).

The model is built on the biologically-based hypotheses that granulosa cell proliferation is controlled by factors of the Bone Morphogenetic Factor (BMP) family (BMP15, GDF9) specifically secreted by the oocyte, and that oocyte growth is, in turn, under the control of granulosa cell-derived factors such as KIT ligand (KITLG) (Otsuka and Shimasaki, 2002; Thomas and Vanderhyden, 2006). From these assumptions, both the average cell cycle duration of each granulosa cell and the effect of each granulosa cell on oocyte growth depend on the cell distance from the surface of the oocyte.

In this model, the proliferation of granulosa cells driven by oocyte-derived BMP factors is illustrated by the equation:

$$
\begin{aligned}
& b(t)=\exp ^{-A_{k}(t) / \lambda_{i}} \\
& X_{k}(t)=(i, j)
\end{aligned}
$$

where $b(\mathrm{t})$ is the probability of instantaneous division for cell $k$ at time $t, A_{k}(\mathrm{t})$ is the age of cell $k$ (time elapsed since its last division), $X_{k}(\mathrm{t})$ is the location of cell $k$ (the radial distance $i$ corresponding to the layer number and the tangential distance $j$ corresponding to the angular location within a cell layer), and $\lambda_{i}$ is related to the average cell cycle duration in cell layer $i$. The value of $\lambda_{i}$ was assumed to increase with the distance of the granulosa cell to the oocyte, in agreement with the lower proliferative activity observed in granulosa cells as they move away from the oocyte and are exposed to increasingly lower concentrations of oocyte-derived mitogenic factors (Da Silva-Buttkus et al., 2008; Gilchrist et al., 2008; Kidder and Vanderhyden, 2010).

The oocyte growth is formulated by a combination of a deterministic law (intrinsic sigmoid-like growth) and a stochastic term driven by KITLG secretion from granulosa cells and acting on the growth rate, as described by the equation: $d_{O}=d_{O}(0)+\int_{0}^{t}\left(d_{O}(s)\right)^{\alpha}\left(1-d_{O}(s)\right)^{\beta} \sum_{i \geq 1} \frac{\kappa_{i} N_{i}(t)}{\log 2(e) \lambda_{i}} d s$

where $d_{O}(\mathrm{t})$ is the oocyte diameter, $\alpha$ and $\beta$ are oocyte growth parameters, $\kappa_{i} N_{i}(t)$ represents the KITLG contribution of layer $i$ to oocyte growth, $N_{i}(t)$ being the cell number in layer $i$. The value of $\kappa_{i}$ was assumed to decrease when the distance of the granulosa cell to the oocyte increases, illustrating both the dilution of the soluble KITLG form due to diffusion, and the high physiological importance of the membrane-bound KITLG form expressed by the first granulosa cell layer, in close contact with the oocyte (Tajima et al., 1998; Thomas et al., 2008). Each $\kappa_{i}$ and $\lambda_{i}$ can be deduced through an appropriate recurrence function from the values $\kappa_{1}$ and $\lambda_{1}$ in the first layer.

The model gives a realistic description of the follicular growth and morphogenesis (Figure 1). The granulosa builds as a compact tissue around the oocyte, and the outer contour of the follicle can be more or less regular depending on the degree of filling of the outside layer, in agreement with histological observations. Moreover, the model supports the previously proposed hypothesis that follicles are constructed by the radial proliferation of granulosa cell clones (Telfer et al., 1988; Boland and Gosden, 1994). An example of clonal territory formed from a given progenitor cell is shown (blue cells) in Figure 1.

\subsection{Genetic control of follicular morphogenesis}

In sheep and mouse, some natural or experimental mutations are known to affect the morphogenesis of preantral follicles. Our mathematical model can help to study the effects of these mutations on the balance between oocyte growth and granulosa cell proliferation. In sheep, the Fec $X^{I}$ Inverdale mutation in the BMP15 gene is known to impair the production of 
biologically active BMP15 (Galloway et al., 2000), whereas the $F e c B^{B}$ Booroola mutation in the gene encoding the receptor BMPR1B attenuates BMP signaling in granulosa cells, due to a lower sensitivity of the cells to BMP factors (Mulsant et al., 2001; Fabre et al., 2003; Estienne et al., 2015), associated with a lower production of BMP15 by the oocyte (Crawford et al., 2011). In the ovaries of both $F e c X^{I}$ and $F e c B^{B}$ homozygous carrier ewes, follicles contain abnormally large oocytes, and the most severe phenotype is observed in the $\mathrm{Fec} X^{I} / \mathrm{Fec} X^{I}$ ewes which are infertile, due to the arrest of follicular growth at the primary follicle stage (Braw-Tal et al., 1993; Cognié et al., 1998; Wilson et al., 2001). This latter phenotype is reminiscent of that of mice in which the Gdf9 gene (encoding a Bmp15-homolog oocyte-derived factor) has been deleted (Dong et al., 1996), and experiencing a secondary upregulation of Kitlg in granulosa cells (Elvin et al., 1999). In contrast, the development of multilayered follicles containing small oocytes in the inhibin-deficient Inha-/- mice is associated with the down-regulation of Kitlg in granulosa cells (Myers et al., 2009). Using our mathematical model, simulations based on a high value of $\kappa_{1}$ or of the ratio $\kappa_{1} / \lambda_{1}$ give rise to follicles with abnormally large oocytes, that mimics the effects on follicular development of the $F e c B^{B}$ and $F e c X^{I}$ mutations in sheep and of the Gdf9 deletion in mouse. Conversely, simulations based on a low ratio $\kappa_{1} / \lambda_{1}$ give rise to follicles with abnormally small oocytes, mimicking the effects of Inha deletion in mouse (Figure 2). Altogether, the biological data and the simulation results strongly suggest that the balance between the activation level of the BMP and KITLG signaling pathways drives follicular morphogenesis in the early stages of follicular development.

Our model can help to explore the mechanisms underlying the balance between the dynamics of oocyte growth and granulosa cell proliferation in other situations leading to high or low fertility. Imbalance cases can result from natural or experimental mutations in animals, as shown above, but they can also be associated with ovarian pathologies in human. For instance, abnormal follicular morphogenesis has been reported in women suffering from the polycystic ovarian syndrome (Stubbs et al., 2007), but its underlying mechanisms have not yet been investigated.

\section{Follicular selection for ovulation : cellular mechanisms and hormonal control}

3.1. Biological knowledge on granulosa cell dynamics during terminal follicular development

At the time when the small antral follicle (with a diameter between 1 and $2 \mathrm{~mm}$ diameter in sheep) enters the terminal phase of follicular development, its granulosa cells proliferate actively. The proportion of proliferating cells among the whole cell population, also called growth fraction, is the highest and about $75 \%$ (Pisselet et al., 2000). About 5 cell doublings separate the small antral from the preovulatory follicle (with about 6 millions of granulosa cells and $7 \mathrm{~mm}$ diameter in sheep), and the succession of cell cycles is accompanied by progressive functional changes in the cell descendants. During this period of about 8 days, the proliferation rate of the granulosa cells slows down by gradual exit of cells from the cell cycle, while cells become more and more responsive to FSH (in term of FSH-induced cAMP production) and express increasing amounts of inhibin and CYP19A1, the key enzyme for estradiol production. FSH orchestrates these processes by both enhancing cell proliferation and promoting cell differentiation. The final differentiation of the granulosa cells involves their FSH-induced endowment of $\mathrm{LH}$ receptors in follicles larger than $3 \mathrm{~mm}$ diameter. Thereafter, granulosa cells completely stop proliferating and become highly steroidogenic and exquisitely sensitive to LH (Monniaux et al., 1997; Fortune et al., 2001; Scaramuzzi et al., 2011). The main changes in granulosa cell activities during follicular development are illustrated in Supplementary Figure 2 of Appendix A. 
During terminal follicular development, the granulosa cells turn progressively from a FSH-responsive to a FSH-dependent maturation stage, in which they enter apoptosis if their FSH requirement is not fulfilled. It is assumed that the propensity of granulosa cells to enter apoptosis is maximal when they achieve their last proliferation cycle and are highly responsive to $\mathrm{FSH}$, but not yet to $\mathrm{LH}$. When the granulosa cells cross this "vulnerability window", their survival fully depends on FSH fluctuations in their environment. Considering the whole follicle, the transit time of its granulosa cells through this phase of vulnerability and the adequacy of locally bioavailable FSH levels during this transit will determine the cumulative cell loss suffered by the follicle and orientate its trajectory toward ovulation or atresia.

\subsection{Cell-based model of follicular development}

We have designed dynamic models giving a continuous and deterministic description of follicle development, adapted to high numbers of cells (between hundred thousand and millions of cells per follicle) and based on the dynamical repartition of granulosa cells into different cell states (Clément et al., 1997; Clément, 1998; Clément et al., 2002; Echenim et al., 2005; Michel, 2011; Aymard et al., 2012; Clément et al., 2013a; Clément and Monniaux, 2013). In the most complex model, the structuring of the granulosa cell population has been defined in a functional 2D space, where the cellular age (in abscissa) refers to the position within the cell cycle, while the maturity level (in ordinate) accounts for cell differentiation level and sensitivity to FSH (Figure 3, top panel). In this formalism, the spatial domain is divided into sub-domains corresponding to different cellular phases: the phase G1 of the cell cycle, during which cells are sensitive to FSH, the aggregation of phases $\mathrm{S}, \mathrm{G} 2$ and $\mathrm{M}$ (phase SM), during which cells are insensitive to FSH and committed to mitosis, and the phase D (differentiation), during which cells having exited the cell cycle are sensitive to FSH for maturation. An additional sub-domain, situated at the boundary between the proliferation and the differentiation domains, corresponds to the vulnerability window (represented as a hatched area in Figure 3), during which cells can enter apoptosis due to FSH deprivation (except when they are in the SM phase, after the restriction point).

The granulosa cells composing a follicle are spread in the functional domain according to their position within or outside the cell cycle, and their maturity level. The dynamics of the cell density $\varphi_{f}(a, \gamma, t)$ of the follicle $f$ in the age-maturity domain are described by the following master equation:

$$
\frac{\partial \phi_{f}}{\partial t}+\frac{\partial g_{f}\left(a, \gamma, u_{f}(t)\right) \phi_{f}}{\partial a}+\frac{\partial h_{f}\left(a, \gamma, u_{f}(t)\right) \phi_{f}}{\partial \gamma}=-\lambda(a, \gamma, U(t)) \phi_{f}
$$

where the variables $a$ and $\gamma$ correspond respectively to the age and maturity of the follicular cells. The expressions of the aging and maturation velocities, respectively $g_{f}\left(a, \gamma, u_{f}(t)\right)$ and $h_{f}\left(a, \gamma, u_{f}(t)\right)$, as well as that of the cell loss rate through apoptosis $\lambda(a, \gamma, U(t))$, vary according to the spatial location of the cell in the domain; their mathematical formulation is provided in Appendix B). These terms are subject to the control functions $u_{f}(t)$, which reflects the bioavailable level of FSH in follicle $f$ and $U(t)$, which represents plasma FSH. They can be interpreted at the intracellular level since the commitment of granulosa cells to proliferation, differentiation, or apoptosis is controlled by FSH-induced cAMP dynamics (Clément et al., 2001). An output of the model (snapshot in the bottom panel of Figure 3) illustrates the repartition of the granulosa cells of a growing follicle into the different functional sub-domains at a given time of the simulation.

On the follicle scale, interesting model outputs are the growth fraction and mitotic index (percentage of mitoses) of the granulosa cell population, the number of cells lost by apoptosis, and the total cell number. In addition, the follicular maturity corresponds to the follicle 


\section{Monniaux et al. 2016 Multiscale modeling of ovarian follicular development}

production of inhibin and estradiol, that is associated with LH responsiveness, ensures its ability to ovulate and weights its contribution into the endocrine feedback exerted by the ovaries onto the pituitary gland and hypothalamus. The total cell number and follicular maturity correspond respectively to the zeroth-order and the first-order moments of the cell density, defined by:

$m_{f}^{0}(t)=\iint \varphi_{f}(a, \gamma, t) \mathrm{d} a \mathrm{~d} \gamma, \quad m_{f}^{1}(t)=\iint \gamma \varphi_{f}(a, \gamma, t) \mathrm{d} a \mathrm{~d} \gamma$.

The changes of these outputs with time give an in-depth cellular and functional description of the dynamics of follicle development toward ovulation or atresia.

\subsection{Follicle competition for ovulation}

From the available biological data, the ovulatory follicle(s) is (are) selected within a cohort of antral growing follicles, also called a follicular wave, whose emergence and growth are triggered by relatively high blood concentrations of FSH (Ireland et al., 2000; Ginther et al., 2001; Scaramuzzi et al., 2011). Each follicle of the cohort secretes increasing amounts of inhibin and estradiol, relative to its cell number and cell maturity level, during its development. The cumulated contributions of all growing follicles to the release of estradiol and inhibin by the ovaries lead to a drop in FSH secretion by the pituitary gland, and the follicles producing the highest hormonal outputs take progressively the control of FSH secretion. The drop in plasma FSH concentrations is at the source of the selection process for ovulation occurring within the follicle population. A hierarchy based on the functional heterogeneity among follicles of the cohort is established progressively, and the follicles become atretic when FSH concentrations fall below the threshold needed to sustain their development. In a mono-ovulating species (such as human, cattle, horse, sheep), only the most mature follicle can survive in the presence of decreasing concentrations of FSH. This follicle has acquired the most developed vascularization and its granulosa cells are the first to become LH responsive, before those of all other follicles in the cohort; it completes its development thanks to LH support until the preovulatory stage, while the other follicles degenerate by atresia.

Our cell-based model describing follicular development takes into account the hormonal feedback loop involving the growing ovarian follicles and pituitary gland (for review: (Clément and Monniaux, 2013)). The ovarian maturity is defined as the sum of the maturities of all follicles in the cohort:

$$
M(t)=\sum_{f} m_{f}^{1}(t)
$$

The global control variable $U(t)$ represents FSH concentrations in plasma, and is a decreasing sigmoidal function of $M(t)$. The local control $u_{f}(t)$ represents FSH bioavailable intrafollicular concentrations, and is proportional to $U(t)$, with a rate evolving as an increasing sigmoidal function of $m_{f}^{1}(t)$, that takes into account the increase in vascularization and bioavailable FSH during follicle maturation. The mathematical formulations of $U(t)$ and $u_{f}(t)$ are provided in Appendix B.

This model is clearly multiscale in nature. Outputs can be obtained at two embedded microscopic scales, i.e. the granulosa cells and the granulosa cell populations, and two embedded macroscopic scales, one considering the follicle (size, cell number, maturity) as an individual, the other the ovarian hormonal release integrating the contribution of all granulosa cells in the cohort of growing follicles. In this model, the separation between the individual trajectories of follicles lies upon differences in the distribution of the cell populations making up each follicle among the phases G1, SM and D of the functional domain. These differences result in differential timings in the maturation steps marking follicular development (as the 


\section{Monniaux et al. 2016 Multiscale modeling of ovarian follicular development}

complete switch to differentiation or escape from vulnerability window) and contrasted total cell numbers and maturity levels at the time of ovulation, ultimately determining the fate of each follicle, i.e. ovulation or atresia.

\subsection{Calibration of interacting ovulatory and atretic trajectories}

The complexity of our mechanistic model coupling cell kinetics with population dynamics, associated with the scarcity of quantitative and kinetic biological data (particularly at the microscopic scale) raises challenging questions to calibrate the model parameters, that we have recently addressed (Aymard et al., 2016). Combining data on follicular growth (changes in follicular diameter with time assessed by ultrasonography (Ravindra et al., 1994) or histology (Turnbull et al., 1977)) with data on granulosa cell numbers according to the follicular diameter (Tsonis et al., 1984), it has been possible to build a data set relating the cell number to time (i.e. follicle age) for the trajectory of an ovulatory follicle in sheep (Clément et al., 1997). This data set was used as a basis for the parameter calibration strategy, to define both the time (and corresponding cell number) when the follicles switch from a FSHresponsive to a FSH-dependent status, and the time when they are selected as future ovulatory follicles. The pattern of FSH changes during the growth of the follicular cohort was assessed in a more direct way from time series of FSH plasma concentrations along the ovarian cycle (Ravindra et al., 1994; Toosi et al., 2010). Using these data, the specific assumptions of the model and multi-objective functions designed along the different calibration steps, it was possible to obtain distinct sets of parameters discriminating the ovulatory trajectories from the atretic ones in a FSH-poor environment (Aymard et al., 2016).

An example of simulation output for an ovulatory / atretic pair of follicles is presented in the top panels of Figure 4 (solid lines). To visualize the contribution of the apoptotic process in the dynamics, the same pair is also followed in the case when the apoptosis rate is deactivated (dashed lines); the selection is then not operated and the former atretic follicle becomes able to ovulate. This result agrees with the biological concept that there is no predestination of the follicle fate, but that the cell sensitivity to the hormonal control is at the source of the selection. The bottom panels of Figure 4 illustrate another example of simulation outputs with a cohort of 10 follicles. In this simulation, all follicles start with the same normalized cell number, but with random perturbations (in the $\pm 10 \%$ range) of the values of the parameters which govern the maturation velocities. The follicles are sorted amongst ovulatory follicles (black solid lines) and atretic ones (dashed blue lines). At the ovulation time (about 8 days, when the cumulated ovarian maturity has reached a threshold level sufficient to trigger ovulation), 3 follicles of the cohort are able to ovulate.

The multiscale model of follicular development is a useful tool to study the mechanisms regulating the number of ovulations (ovulation rate) in different breeds and lines of sheep. In this naturally mono-ovulating species, the presence of specific mutations affecting factors of the BMP family or their receptors has been associated with the occurrence of multiple ovulations and the advancement of follicular maturation, so that follicles ovulate at a smaller size, compared to follicles of wild-type ewes (McNatty et al., 2005a; McNatty et al., 2005b; Fabre et al., 2006). The physiological mechanisms responsible for this ovarian phenotype have not been fully understood up to now. Using the multiscale model through intensive simulations with random selection of parameter values, one can expect to recover for each parameter a distribution compatible with the ovulation number and ovulatory size of follicles for each genetic model. For instance, the simulation outputs depicted in the bottom panels of Figure 4 show that the final cell mass and maturity of the ovulatory follicles are modulated by small perturbations in parameters affecting the aging and maturation velocities. Elucidating the mechanisms resulting in a given ovulation number is not a trivial question since the polyovulatory strategies involve different mechanisms acting on the follicle populations (e.g. size 


\section{Monniaux et al. 2016 Multiscale modeling of ovarian follicular development}

of the cohort at terminal recruitment, rate of selection) or individual follicles (e.g. ovulatory size, final cell number, cellular steroidogenic potential) and endocrine feedbacks (sensitivity of pituitary or hypothalamic cells to ovarian hormones). The model helps us to investigate these mechanisms and especially (i) the compromise between proliferation and differentiation that tunes and possibly optimizes the final cell number and corresponding maturity at ovulation time (Clément, 1998; Clément et al., 2013a) (ii) the quite antagonistic constraints weighing on the atresia rate, that should both limit cell loss in ovulatory follicles and penalize sufficiently the atretic ones to deplete their cell content, and (iii) the degrees of freedom operating at the level of the ovaries, pituitary gland or hypothalamus (Echenim et al., 2005). The corresponding qualitative and semi-quantitative scenarios would be substantiated further if the model could be fueled with proper combinatory data sets describing both the atretic and ovulatory trajectories, which has remained beyond reach on the experimental ground up to now. In the same spirit, subject to data availability, the model could be extended to other species characterized by one (human, cattle, horse) or multiple ovulations (rodents, pigs) at each ovarian cycle, and to pathological situations of dysovulation or anovulation.

\section{Conclusion}

The multiscale and dynamic models that we have designed to study follicular development are based on the embedding of physiological mechanisms into the cell scale. These mechanistic models have been built on biological hypotheses and concepts and result in mathematical objects that raise challenging numerical (Aymard et al., 2013) and theoretical questions (Shang, 2013). Even if the available quantitative data are scarce and not truly kinetic, the design of precise biological specifications from combined literature sources enabled us to constrain the quantitative outputs on the different scales and calibrate parameters entering the microscopic functions from macroscopic observations.

Despite their difficult calibration, these models are useful tools for addressing ovarian physiopathological situations. Moreover, they can be proposed as generic modeling environments to study various developmental processes and cell interaction mechanisms. The model of follicular morphogenesis based on the molecular dialogue between two neighbouring cell types takes into account the secretion, diffusion and action of factors in a spatio-temporal formalism which could be applied to organogenesis in embryo and fetus, or tumor development. In the model dedicated to terminal follicular development, we have addressed very generic processes of cell developmental biology such as the dynamical repartition of cell populations into different states (namely proliferation, differentiation and apoptosis), the regulation of cell cycle progression and exit toward apoptosis or differentiation by an extracellular factor, and the feedback of cell populations on their own renewal. The simulations enable real-time monitoring of biological markers such as the growth fraction and mitotic index, and the distribution of cells within the cell cycle. At this stage, the information provided by the models is richer than what can be obtained in vivo or in primary cell cultures. Yet, there is hope that the adaptation of new methodologies (Sakaue-Sawano et al., 2008; Hoppe et al., 2014) to the physiological context of a tissue will help to match the in silico time-lapse monitoring of cell fates or cell populations to in vivo measures. 


\section{References}

Aymard, B., Clément, F., Coquel, F. and Postel, M. (2012) Numerical simulation of the selection process of the ovarian follicles. Esaim Proc. 38, 99-117

Aymard, B., Clément, F., Coquel, F. and Postel, M. (2013) A numerical method for transport equations with discontinuous flux functions: Application to mathematical modeling of cell dynamics. SIAM J. Sci. Comput. 35, A2242-A2468

Aymard, B., Clément, F., Monniaux, D. and Postel, M. (2016) Cell-kinetics based calibration of a multiscale model of structured cell populations in ovarian follicles. To appear in SIAM J. Appl. Math.

Boland, N.I. and Gosden, R.G. (1994) Clonal analysis of chimaeric mouse ovaries using DNA in situ hybridization. J Reprod Fertil 100, 203-210

Braw-Tal, R., McNatty, K.P., Smith, P., Heath, D.A., Hudson, N.L., Phillips, D.J., McLeod, B.J. and Davis, G.H. (1993) Ovaries of ewes homozygous for the X-linked Inverdale gene (FecXI) are devoid of secondary and tertiary follicles but contain many abnormal structures. Biol. Reprod. 49, 895-907

Clément, F. (1998) Optimal control of the cell dynamics in the granulosa of ovulatory follicles. Math. Biosci. 152, 123-142

Clément, F., Coron, J.M. and Shang, P. (2013a) Optimal control of cell mass and maturity in a model of follicular ovulation. SIAM J Control Optim 51, 824-847

Clément, F., Gruet, M.A., Monget, P., Terqui, M., Jolivet, E. and Monniaux, D. (1997) Growth kinetics of the granulosa cell population in ovarian follicles: an approach by mathematical modelling. Cell Prolif. 30, 255-270

Clément, F., Michel, P., Monniaux, D. and Stiehl, T. (2013b) Coupled somatic cell kinetics and germ cell growth: multiscale model-based insight on ovarian follicular development. Multiscale Model Simul 11, 719-746

Clément, F. and Monniaux, D. (2013) Multiscale modelling of ovarian follicular selection. Prog. Biophys. Mol. Biol. 113, 398-408

Clément, F., Monniaux, D., Stark, J., Hardy, K., Thalabard, J.C., Franks, S. and Claude, D. (2001) Mathematical model of FSH-induced cAMP production in ovarian follicles. Am. J. Physiol. Endocrinol. Metab. 281, E35-53

Clément, F., Monniaux, D., Thalabard, J.C. and Claude, D. (2002) Contribution of a mathematical modelling approach to the understanding of the ovarian function. C R Biol 325, 473-485

Cognié, Y., Benoit, F., Poulin, N., Khatir, H. and Driancourt, M.A. (1998) Effect of follicle size and of the FecB Booroola gene on oocyte function in sheep. J Reprod Fertil 112, 379-386

Crawford, J.L., Heath, D.A., Reader, K.L., Quirke, L.D., Hudson, N.L., Juengel, J.L. and McNatty, K.P. (2011) Oocytes in sheep homozygous for a mutation in bone morphogenetic protein receptor $1 \mathrm{~B}$ express lower mRNA levels of bone morphogenetic protein 15 but not growth differentiation factor 9. Reproduction 142, 53-61

Da Silva-Buttkus, P., Jayasooriya, G.S., Mora, J.M., Mobberley, M., Ryder, T.A., Baithun, M., Stark, J., Franks, S. and Hardy, K. (2008) Effect of cell shape and packing density on granulosa cell proliferation and formation of multiple layers during early follicle development in the ovary. J Cell Sci 121, 3890-3900

Dong, J., Albertini, D.F., Nishimori, K., Kumar, T.R., Lu, N. and Matzuk, M.M. (1996) Growth differentiation factor-9 is required during early ovarian folliculogenesis. Nature 383, 531-535

Echenim, N., Monniaux, D., Sorine, M. and Clément, F. (2005) Multi-scale modeling of the follicle selection process in the ovary. Math. Biosci. 198, 57-79

Elvin, J.A., Clark, A.T., Wang, P., Wolfman, N.M. and Matzuk, M.M. (1999) Paracrine actions of growth differentiation factor-9 in the mammalian ovary. Mol Endocrinol 13, 1035-1048 
Estienne, A., Pierre, A., di Clemente, N., Picard, J.Y., Jarrier, P., Mansanet, C., Monniaux, D. and Fabre, S. (2015) Anti-Mullerian hormone regulation by the bone morphogenetic proteins in the sheep ovary: deciphering a direct regulatory pathway. Endocrinology 156, 301-313

Fabre, S., Pierre, A., Mulsant, P., Bodin, L., Di Pasquale, E., Persani, L., Monget, P. and Monniaux, D. (2006) Regulation of ovulation rate in mammals: contribution of sheep genetic models. Reprod. Biol. Endocrinol. 4, 20

Fabre, S., Pierre, A., Pisselet, C., Mulsant, P., Lecerf, F., Pohl, J., Monget, P. and Monniaux, D. (2003) The Booroola mutation in sheep is associated with an alteration of the bone morphogenetic protein receptor-IB functionality. J. Endocrinol. 177, 435-444

Fortune, J.E., Rivera, G.M., Evans, A.C. and Turzillo, A.M. (2001) Differentiation of dominant versus subordinate follicles in cattle. Biol. Reprod. 65, 648-654

Galloway, S.M., McNatty, K.P., Cambridge, L.M., Laitinen, M.P., Juengel, J.L., Jokiranta, T.S., McLaren, R.J., Luiro, K., Dodds, K.G., Montgomery, G.W., et al. (2000) Mutations in an oocyte-derived growth factor gene (BMP15) cause increased ovulation rate and infertility in a dosage-sensitive manner. Nat. Genet. 25, 279-283

Gilchrist, R.B., Lane, M. and Thompson, J.G. (2008) Oocyte-secreted factors: regulators of cumulus cell function and oocyte quality. Hum. Reprod. Update 14, 159-177

Ginther, O.J., Beg, M.A., Bergfelt, D.R., Donadeu, F.X. and Kot, K. (2001) Follicle selection in monovular species. Biol. Reprod. 65, 638-647

Gougeon, A. (1996) Regulation of ovarian follicular development in primates: facts and hypotheses. Endocr. Rev. 17, 121-155

Hoppe, P.S., Coutu, D.L. and Schroeder, T. (2014) Single-cell technologies sharpen up mammalian stem cell research. Nat Cell Biol 16, 919-927

Ireland, J.J., Mihm, M., Austin, E., Diskin, M.G. and Roche, J.F. (2000) Historical perspective of turnover of dominant follicles during the bovine estrous cycle: key concepts, studies, advancements, and terms. J Dairy Sci 83, 1648-1658

Kidder, G.M. and Mhawi, A.A. (2002) Gap junctions and ovarian folliculogenesis. Reproduction 123, 613-620

Kidder, G.M. and Vanderhyden, B.C. (2010) Bidirectional communication between oocytes and follicle cells: ensuring oocyte developmental competence. Can. J. Physiol. Pharmacol. 88, 399-413

Lundy, T., Smith, P., O'Connell, A., Hudson, N.L. and McNatty, K.P. (1999) Populations of granulosa cells in small follicles of the sheep ovary. J Reprod Fertil 115, 251-262

McGee, E.A. and Hsueh, A.J. (2000) Initial and cyclic recruitment of ovarian follicles. Endocr. Rev. 21, 200-214

McNatty, K.P., Galloway, S.M., Wilson, T., Smith, P., Hudson, N.L., O'Connell, A., Bibby, A.H., Heath, D.A., Davis, G.H., Hanrahan, J.P., et al. (2005a) Physiological effects of major genes affecting ovulation rate in sheep. Genet Sel Evol 37 Suppl 1, S25-38

McNatty, K.P., Smith, P., Moore, L.G., Reader, K., Lun, S., Hanrahan, J.P., Groome, N.P., Laitinen, M., Ritvos, O. and Juengel, J.L. (2005b) Oocyte-expressed genes affecting ovulation rate. Mol. Cell. Endocrinol. 234, 57-66

Michel, P. (2011) Multiscale modeling of follicular ovulation as a mass and maturity dynamical system. Multiscale Model Simul 9, 282-313

Monget, P., Bobe, J., Gougeon, A., Fabre, S., Monniaux, D. and Dalbies-Tran, R. (2012) The ovarian reserve in mammals: a functional and evolutionary perspective. Mol. Cell. Endocrinol. 356, 2-12

Monniaux, D., Clément, F., Dalbies-Tran, R., Estienne, A., Fabre, S., Mansanet, C. and Monget, P. (2014) The ovarian reserve of primordial follicles and the dynamic reserve of antral growing follicles: what is the link? Biol. Reprod. 90, 85 
Monniaux, D., Huet, C., Besnard, N., Clément, F., Bosc, M., Pisselet, C., Monget, P. and Mariana, J.C. (1997) Follicular growth and ovarian dynamics in mammals. J. Reprod. Fertil. Suppl. 51, 3-23

Mulsant, P., Lecerf, F., Fabre, S., Schibler, L., Monget, P., Lanneluc, I., Pisselet, C., Riquet, J., Monniaux, D., Callebaut, I., et al. (2001) Mutation in bone morphogenetic protein receptor-IB is associated with increased ovulation rate in Booroola Merino ewes. Proc. Natl. Acad. Sci. U. S. A. 98, 5104-5109

Myers, M., Middlebrook, B.S., Matzuk, M.M. and Pangas, S.A. (2009) Loss of inhibin alpha uncouples oocyte-granulosa cell dynamics and disrupts postnatal folliculogenesis. Dev. Biol. 334, 458-467

Otsuka, F. and Shimasaki, S. (2002) A negative feedback system between oocyte bone morphogenetic protein 15 and granulosa cell kit ligand: its role in regulating granulosa cell mitosis. Proc. Natl. Acad. Sci. U. S. A. 99, 8060-8065

Pisselet, C., Clément, F. and Monniaux, D. (2000) Fraction of proliferating cells in granulosa during terminal follicular development in high and low prolific sheep breeds. Reprod. Nutr. Dev. 40, 295-304

Ravindra, J.P., Rawlings, N.C., Evans, A.C. and Adams, G.P. (1994) Ultrasonographic study of ovarian follicular dynamics in ewes during the oestrous cycle. J Reprod Fertil 101, 501-509

Rodgers, R.J. and Irving-Rodgers, H.F. (2010) Formation of the ovarian follicular antrum and follicular fluid. Biol. Reprod. 82, 1021-1029

Sakaue-Sawano, A., Kurokawa, H., Morimura, T., Hanyu, A., Hama, H., Osawa, H., Kashiwagi, S., Fukami, K., Miyata, T., Miyoshi, H., et al. (2008) Visualizing spatiotemporal dynamics of multicellular cell-cycle progression. Cell 132, 487-498

Scaramuzzi, R.J., Baird, D.T., Campbell, B.K., Driancourt, M.A., Dupont, J., Fortune, J.E., Gilchrist, R.B., Martin, G.B., McNatty, K.P., McNeilly, A.S., et al. (2011) Regulation of folliculogenesis and the determination of ovulation rate in ruminants. Reprod. Fertil. Dev. 23, 444-467

Shang, P. (2013) Cauchy problem for multiscale conservation laws: Application to structured cell populations. J. Math. Anal. Appl. 401, 896-920

Stubbs, S.A., Stark, J., Dilworth, S.M., Franks, S. and Hardy, K. (2007) Abnormal preantral folliculogenesis in polycystic ovaries is associated with increased granulosa cell division. J Clin Endocrinol Metab 92, 4418-4426

Tajima, Y., Moore, M.A., Soares, V., Ono, M., Kissel, H. and Besmer, P. (1998) Consequences of exclusive expression in vivo of Kit-ligand lacking the major proteolytic cleavage site. Proc. Natl. Acad. Sci. U. S. A. 95, 11903-11908

Telfer, E., Ansell, J.D., Taylor, H. and Gosden, R.G. (1988) The number of clonal precursors of the follicular epithelium in the mouse ovary. J Reprod Fertil 84, 105-110

Thomas, F.H., Ismail, R.S., Jiang, J.Y. and Vanderhyden, B.C. (2008) Kit ligand 2 promotes murine oocyte growth in vitro. Biol. Reprod. 78, 167-175

Thomas, F.H. and Vanderhyden, B.C. (2006) Oocyte-granulosa cell interactions during mouse follicular development: regulation of kit ligand expression and its role in oocyte growth. Reprod. Biol. Endocrinol. 4, 19

Toosi, B.M., Seekallu, S.V. and Rawlings, N.C. (2010) Effects of the rate and duration of physiological increases in serum FSH concentrations on emergence of follicular waves in cyclic ewes. Biol. Reprod. 83, 648-655

Tsonis, C.G., Carson, R.S. and Findlay, J.K. (1984) Relationships between aromatase activity, follicular fluid oestradiol-17 beta and testosterone concentrations, and diameter and atresia of individual ovine follicles. J Reprod Fertil 72, 153-163

Turnbull, K.E., Braden, A.W. and Mattner, P.E. (1977) The pattern of follicular growth and atresia in the ovine ovary. Aust. J. Biol. Sci. 30, 229-241 
Wilson, T., Wu, X.Y., Juengel, J.L., Ross, I.K., Lumsden, J.M., Lord, E.A., Dodds, K.G., Walling, G.A., McEwan, J.C., O'Connell, A.R., et al. (2001) Highly prolific Booroola sheep have a mutation in the intracellular kinase domain of bone morphogenetic protein IB receptor (ALK-6) that is expressed in both oocytes and granulosa cells. Biol. Reprod. 64, 1225-1235

Zhang, H., Risal, S., Gorre, N., Busayavalasa, K., Li, X., Shen, Y., Bosbach, B., Brannstrom, M. and Liu, K. (2014) Somatic cells initiate primordial follicle activation and govern the development of dormant oocytes in mice. Curr Biol 24, 2501-2508 

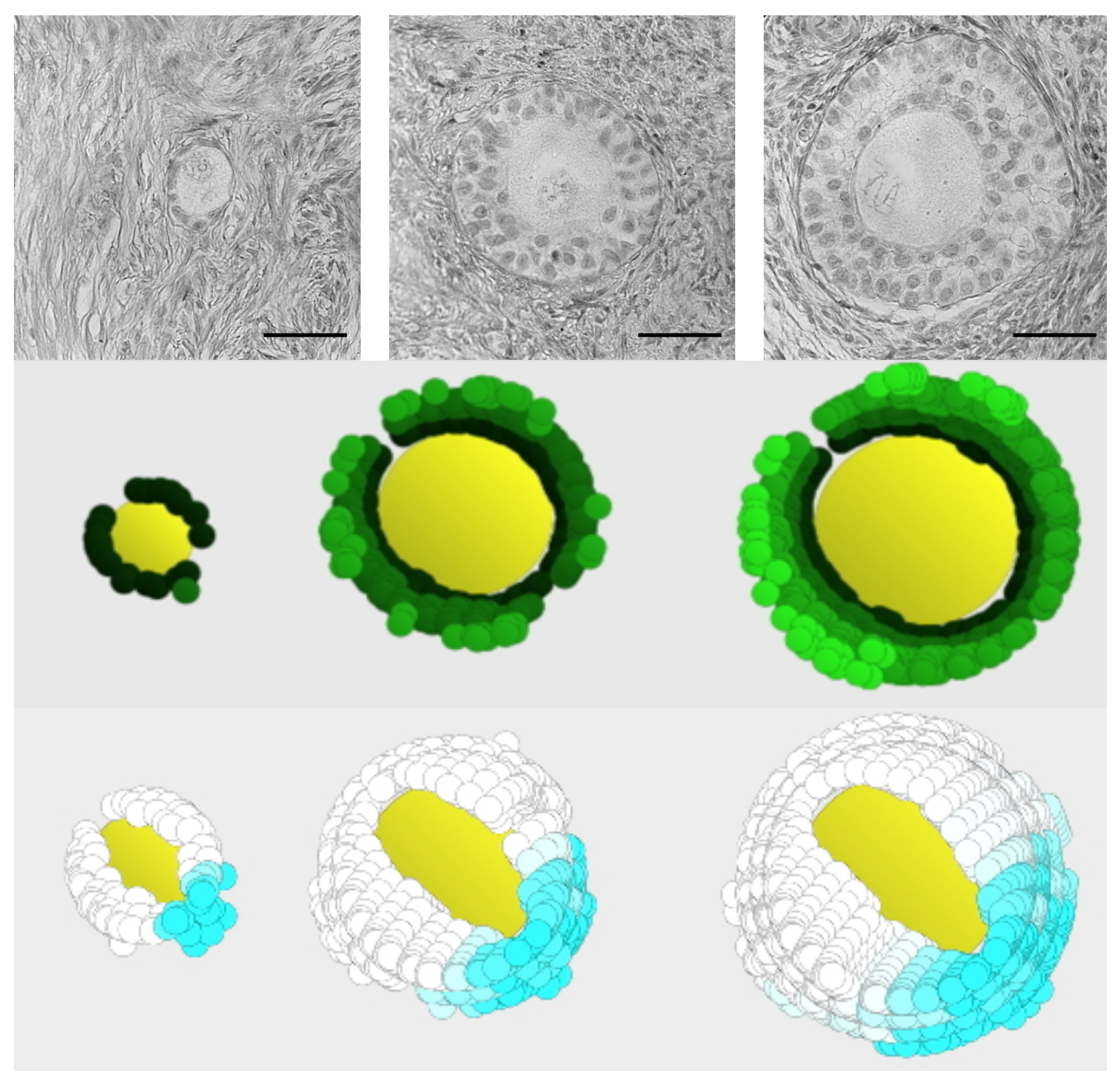

Figure 1: Morphogenesis of small preantral follicles. Top panels: histological appearance of growing follicles, from the primary (on the left) to the 3-4 granulosa cell layer (on the right) stages. The oocyte is the big cell at the center of the follicle. Bar $=50 \mu \mathrm{m}$. Center panels: $3 \mathrm{D}-$ like views of microscopic outputs of the model dedicated to the study of follicular morphogenesis. Part of the mass of proliferating granulosa cells (small green cells) has been removed to visualize the oocyte (big yellow cell). Bottom panels: 3D-like views of mesoscopic outputs showing a clonal territory (blue cells) in the population of proliferating granulosa cells surrounding the oocyte (big yellow cell). In the clonal territory, the intensity of blue staining varies according to the proportion of cells descending from the same ancestor cell. 

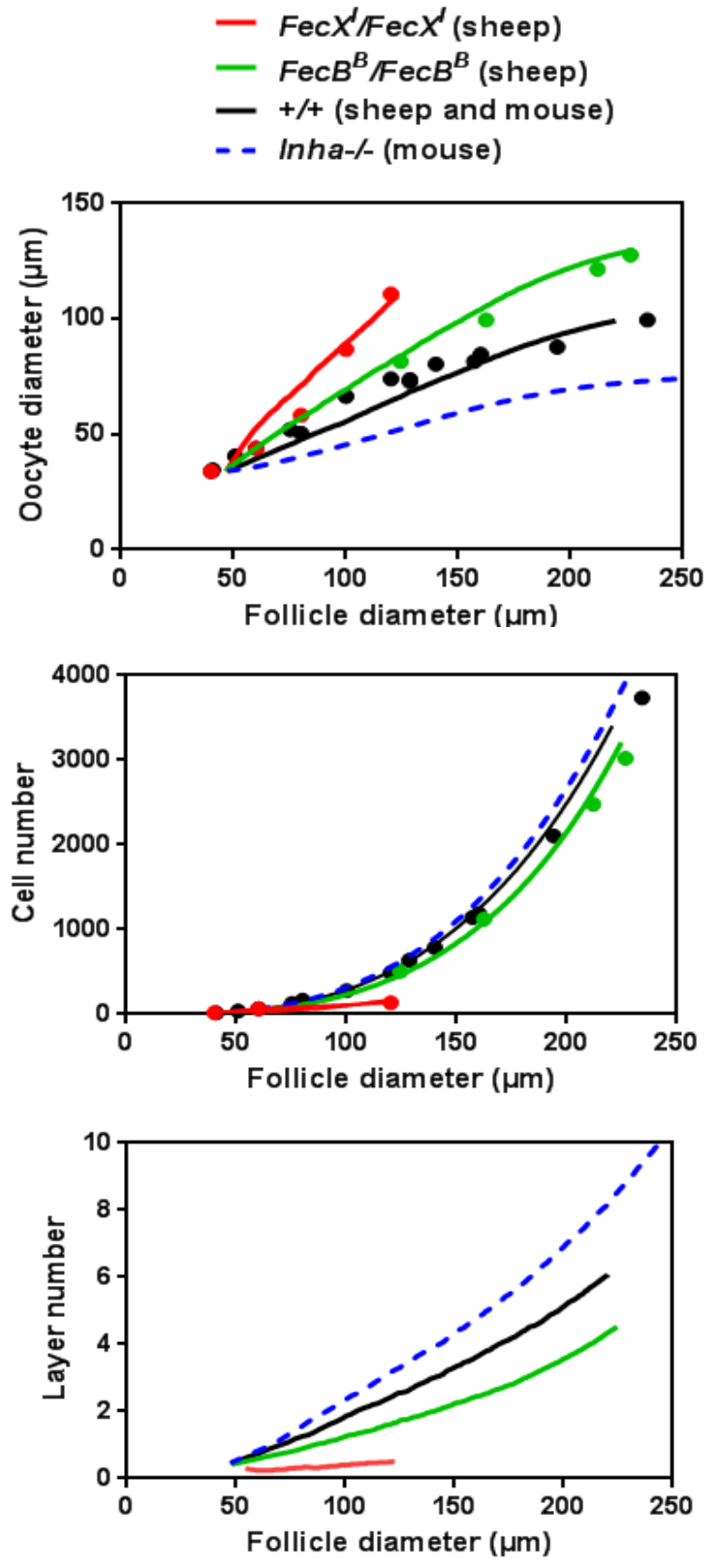

Figure 2: Genetic control of the balance between oocyte growth and granulosa cell proliferation during the growth of small preantral follicles in sheep and mouse. The lines depict different simulation outputs of the model dedicated to the study of follicular morphogenesis. Oocyte growth (oocyte diameter in the top panel) and granulosa cell proliferation (total cell number in the center panel and number of cell layers in the bottom panel) are expressed in function of follicular diameter. The simulation outputs reproduce the imbalance between oocyte growth and granulosa cell proliferation associated with some mutations: abnormally large oocytes in follicles from $F e c B^{B} / F e c B^{B}$ (green lines) and $F e c X^{I} / F e c X^{I}$ (red lines) ewes, and abnormally small oocytes in follicles from Inha-/- (blue dashed lines) mice. In the severe $F e c X^{I} / F e c X^{I}$ ovarian phenotype, follicular growth is arrested before full filling the first granulosa cell layer, leading to sterility of the mutant ewes. Data sets of wild-type (+/+, black points), $F e c B^{B} / F e c B^{B}$ (green points) and $F e c X^{I} / F e c X^{I}$ (red points) ewes, obtained from Braw-Tal et al. (1993), Lundy et al. (1999) and Wilson et al. (2001), are represented in the top and center panels. No truly quantitative data sets are available for Inha-/- mice (Myers et al., 1999). 

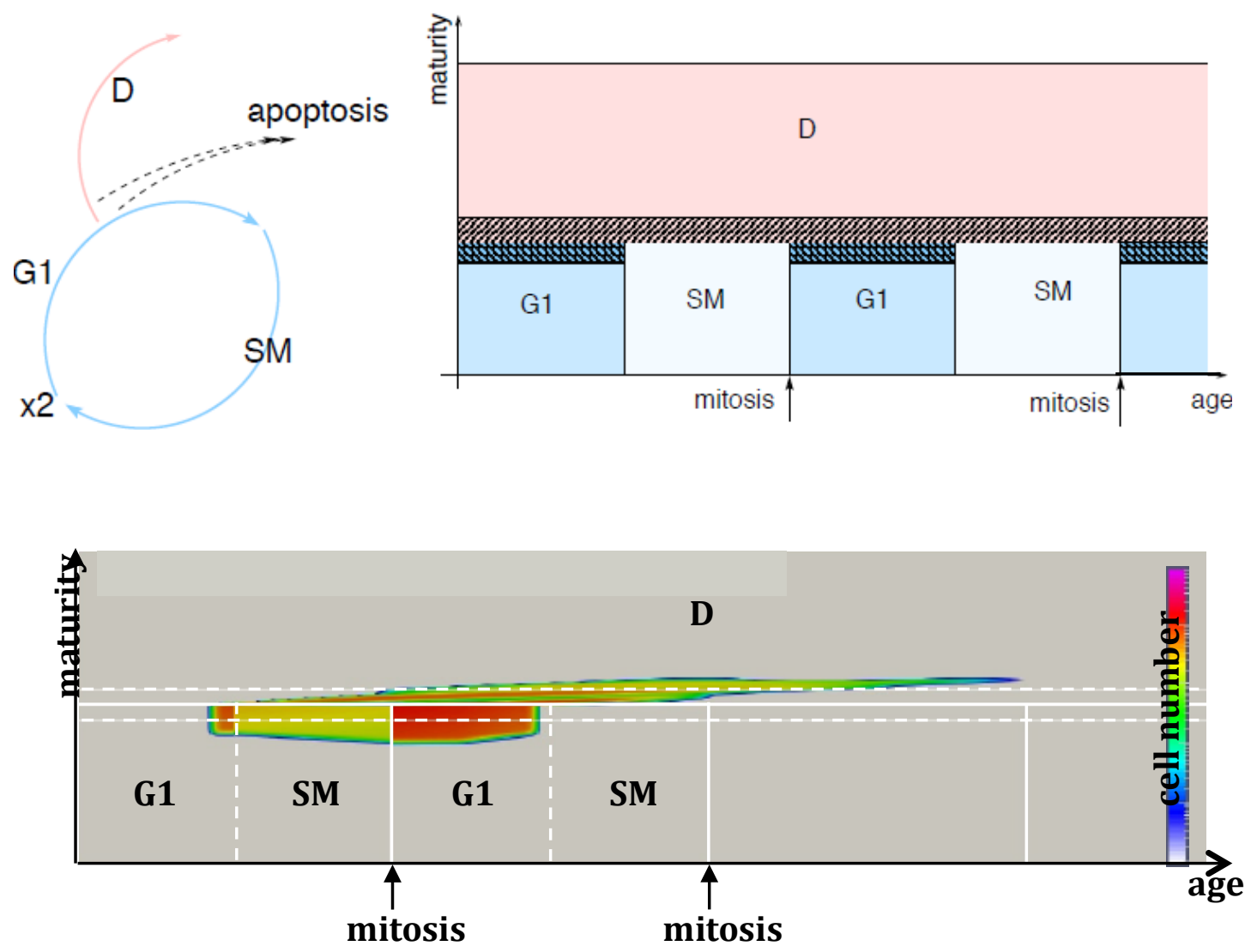

Figure 3: Functional domain for structured granulosa cell populations and microscopic simulation output of the model dedicated to the study of terminal follicular development. Top panels: The population of granulosa cells in a follicle can be subdivided in sub-populations of proliferating cells, differentiated cells having exited the cell cycle, and cells committed to apoptosis, under the control of FSH levels. A functional domain describing the structuring of cell populations has been defined with cell age in abscissa and cell maturity in ordinate. Proliferating cells (blue arrows of the cell cycle and blue G1 and SM sub-domains of the spatial domain) can either continue proliferating, or exit the cycle during the G1 phase and enter a differentiated stage (pink arrow of the cell cycle and pink D sub-domain of the spatial domain). They can also be committed to apoptosis (black dashed arrows) by FSH deprivation when they cross a vulnerability window (hatched area of the spatial domain) located at the boundary between the proliferation and differentiation sub-domains. Bottom panel: Simulation output of the model, illustrating an example of cell repartition in the functional domain. The passage of cells through the SM-G1 interface has resulted in doubling of the cell density. The cell population spread in the D sub-domain includes cells having exited the cell cycle during the G1 phase of the current and former cell cycles. 

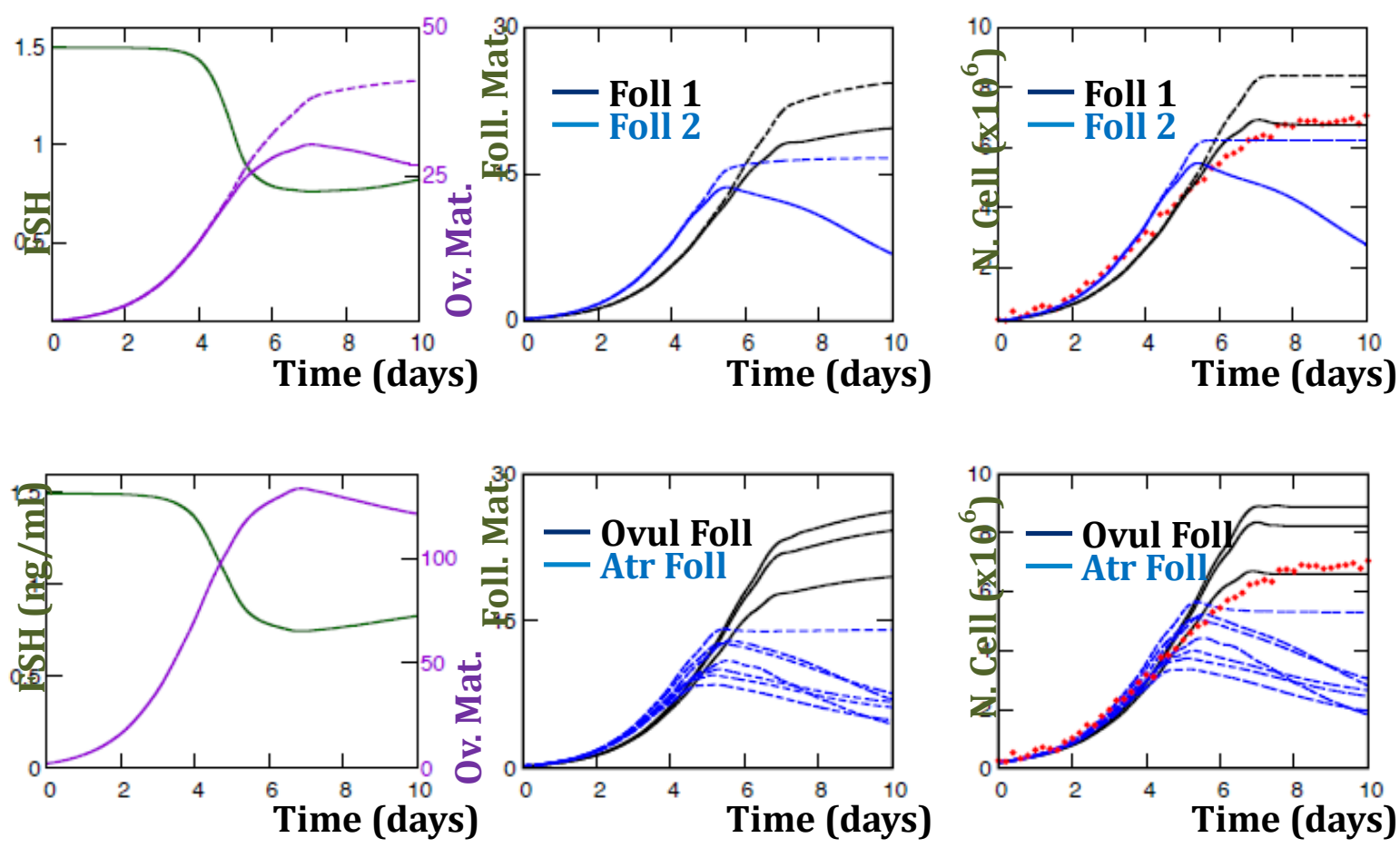

Figure 4: Macroscopic simulation outputs of the model dedicated to the study of terminal follicular development. The panels illustrate different outputs as functions of time for a cohort of 2 follicles (top panels) and 10 follicles (bottom panels). Left panels: plasma FSH and ovarian maturity (which is the sum of the maturities of all follicles in the cohort). Center panels: follicular maturity (expressed in arbitrary units), corresponding for each follicle to its capacity of production of inhibin and estradiol (associated with its responsiveness to gonadotropins). Right panels: Number of granulosa cells per follicle. The red points correspond to an experimental data set elaborated from different bibliographic sources (Clément et al., 1997). In the top panels, the dashed lines correspond to the follicular trajectories when the apoptosis rate is deactivated. In the bottom panels, the solid black lines correspond to the ovulatory follicles and the dashed blue lines to the atretic ones, whose final maturity and cell number are insufficient for ovulation 


\section{Appendix A : Biological basis of the mathematical models dedicated to follicle development in ovary}

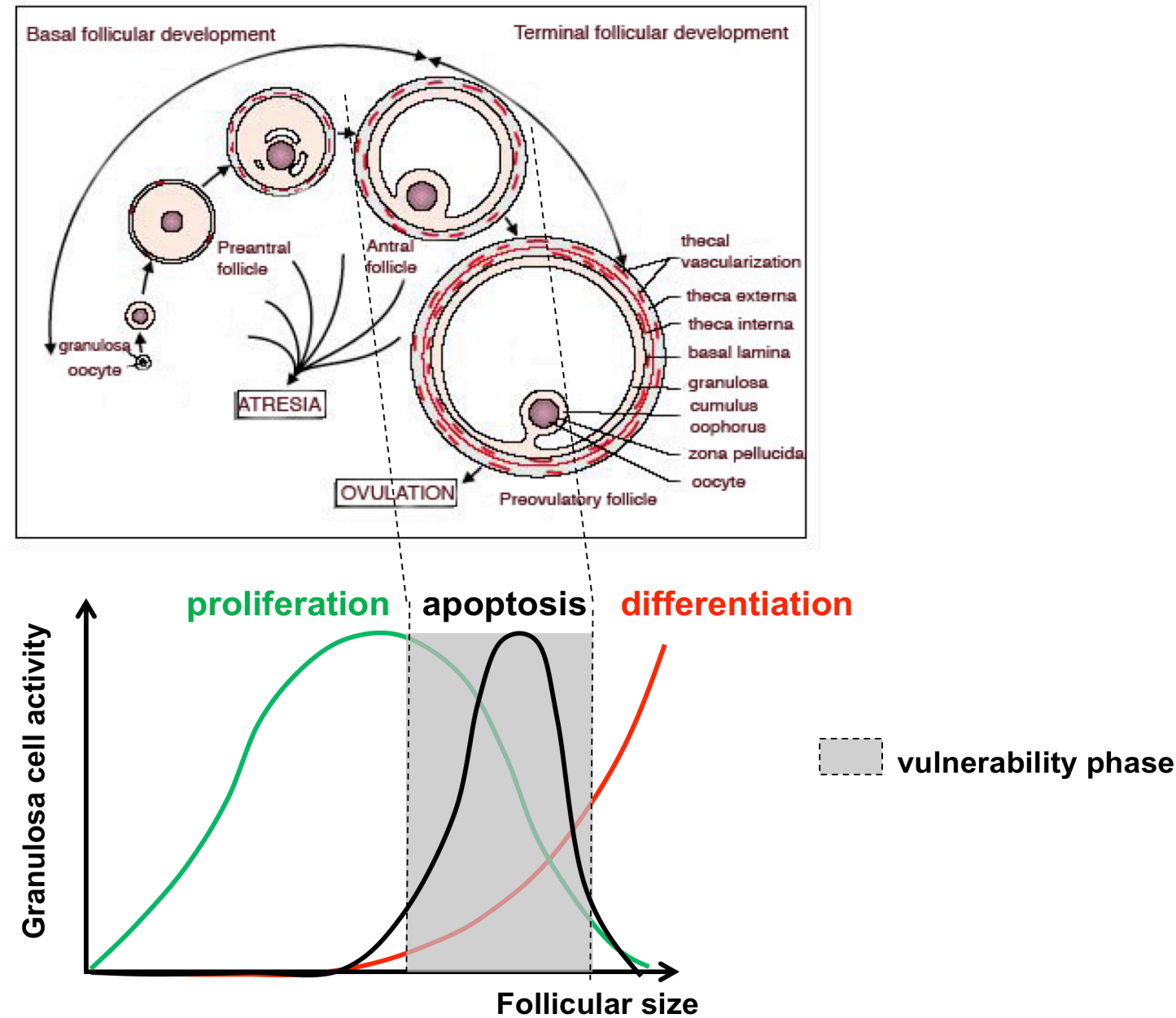

Supplementary Figure 1: Main morphological and functional changes in follicles during follicular development. Top panel: Schematic drawing of the different stages of follicular development. Each growing follicle is composed of a germ cell, named oocyte, surrounded by somatic cells, named granulosa cells. During the phase called "basal follicular development", the oocyte grows and its companion granulosa cells proliferate (preantral follicle stage). Then a vascularized theca differentiates and surrounds the granulosa tissue while small cavities filled with follicular fluid form within the granulosa. Later, these cavities merge, giving rise to a central cavity called antrum (antral follicle stage). During the phase called "terminal follicular development", the antrum enlarges and separates the population of granulosa cells into two main groups, the cumulus cells associated with the oocyte and the mural granulosa cells lining the follicular wall. In ovaries, only $0.01 \%$ of the follicles which have entered growth can reach the final stage of development (preovulatory follicle stage) and ovulate, the others degenerating by a physiological process named atresia. Bottom panel: Functional changes in granulosa cells during follicular growth. When a follicle enters growth, its granulosa cells start proliferating at a low rate, then proliferation rate increases gradually in the multilayered preantral follicle and reaches a maximum in the small antral follicle. Later, the granulosa cells loose progressively their proliferative activity and differentiate into highly steroidogenic cells in the preovulatory follicle. During their shift between proliferation and final differentiation, the granulosa cells are particularly vulnerable and can enter apoptosis if their hormonal requirements (particularly their FSH requirement, see Supplementary Figure 2) are not fulfilled. This high propensity to apoptosis of granulosa cells affects the large antral follicle during its terminal development; it constitutes the basis of the selection process which occurs among the cohort of follicles having entered the terminal phase of follicular development. 


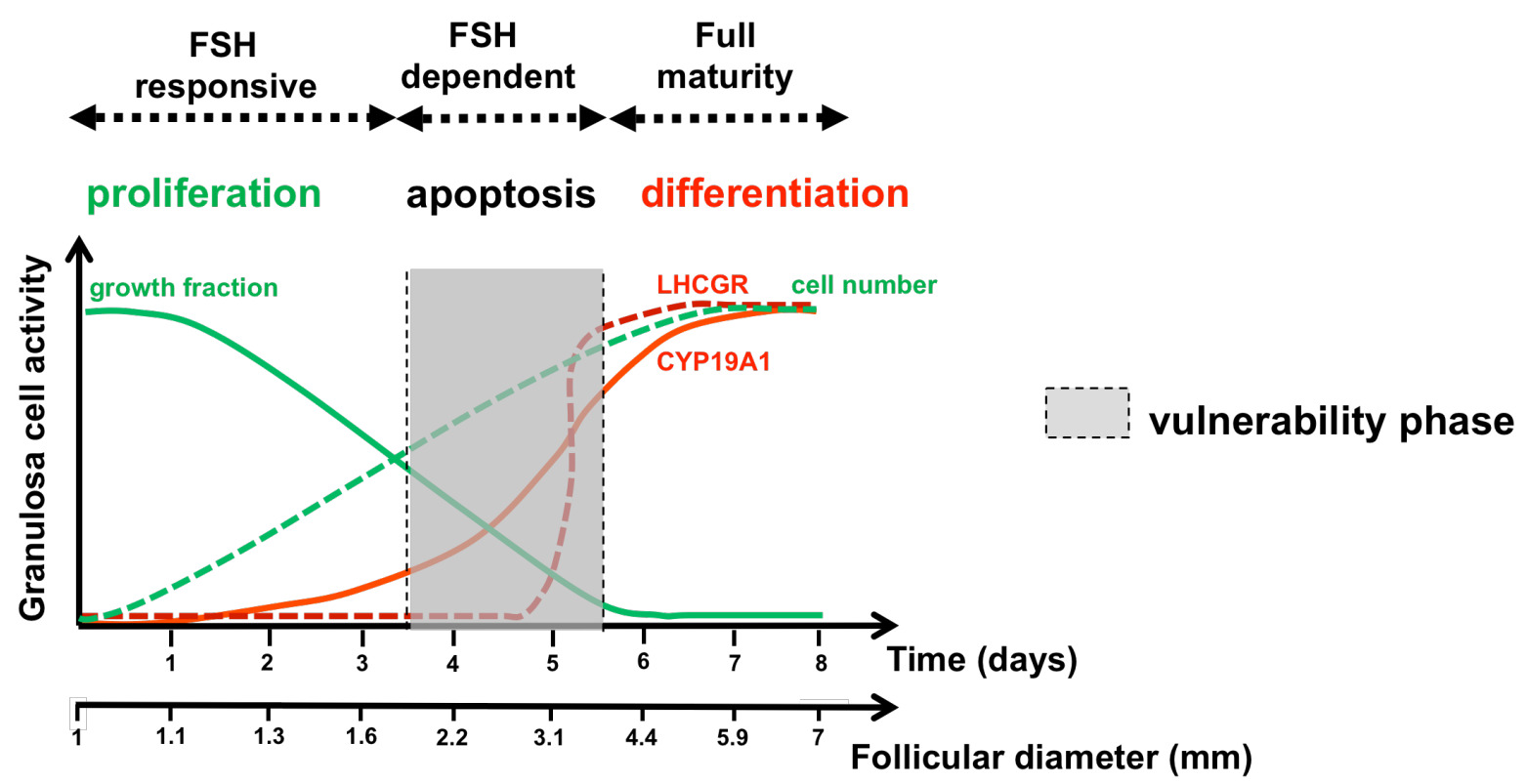

Supplementary Figure 2: Functional changes in granulosa cells during terminal follicular development in sheep. In sheep ovary, the development of an antral follicle between $1 \mathrm{~mm}$ (follicular stage corresponding to the highest proliferation rate of granulosa cells) and $7 \mathrm{~mm}$ diameter (preovulatory follicle stage) lasts about 8 days. During this period, the growth fraction (proportion of proliferating cells) of granulosa cells decreases while the cell number increases steadily up to a plateau of about 6 millions of cells per follicle. This loss in proliferative activity is accompanied by important functional changes in granulosa cells, such as a high increase in the expression of genes encoding CYP19A1 (key enzyme for estradiol production) and LHCGR (receptor to the luteinizing hormone LH secreted by the pituitary gland). These differentiation changes are induced and controlled by another pituitary hormone named FSH (follicle stimulating hormone), which controls the terminal development of follicles. In antral follicles between 1 and $2 \mathrm{~mm}$ diameter, granulosa cells are described as FSH responsive; FSH can enhance their proliferation rate and promote their differentiation. Then, in follicles between 2 and $4 \mathrm{~mm}$ diameter, granulosa cells are exquisitely sensitive to FSH for sustaining their proliferation and differentiation rates and become FSH dependent; their survival is compromised when their FSH requirements are not fulfilled. Finally, in the largest follicles which have exited this vulnerability phase, granulosa cells have completely stopped proliferating but are fully differentiated, they can survive in an FSH-poor environment, thanks to their ability to respond to LH. At ovulation time, only the most mature follicles, bearing LH receptors on their granulosa cells, can ovulate in response to the $\mathrm{GnRH}$ (gonadotropin releasing hormone)induced preovulatory LH discharge from the pituitary gland. 


\section{Appendix B : Formulation of the main equations for the multiscale model of follicular selection for ovulation}

The expressions of the cell aging and maturation velocities, respectively $g_{f}\left(a, \gamma, u_{f}(t)\right)$ and $h_{f}\left(a, \gamma, u_{f}(t)\right)$, as well as that of the cell loss rate through apoptosis $\lambda(a, \gamma, U(t))$, vary according to the spatial location of the cell in the age-maturity domain. In closed control loops, the global and local control variables, $U(t)$ and $u_{f}(t)$, are expressed respectively as functions of the ovarian and follicular maturities. In all equations, variables $a$ and $\gamma$ correspond respectively to the age and maturity of follicular cells, $U(t)$ represents plasma FSH levels and the local control $u_{f}(t)$ represents bioavailable intrafollicular FSH concentrations.

1- Aging velocity $g_{f}\left(a, \gamma, u_{f}(t)\right)$

$g_{f}\left(a, \gamma, u_{f}(t)\right)=\left\{\begin{array}{cc}\gamma_{1} u_{f}(t)+\gamma_{2} & \text { in phase G1 } \\ 1 & \text { in phases SM and D }\end{array}\right.$

where $\gamma_{1}$ and $\gamma_{2}$ are real positive constants. The transit time in phase G1 is modulated by the control term $u_{f}(t)$, while the cell age varies as time in other phases. In any case, the age is a monotonically increasing function of time.

2- Maturation velocity $h_{f}\left(a, \gamma, u_{f}(t)\right)$,

$h_{f}\left(a, \gamma, u_{f}(t)\right)=\left\{\begin{array}{lr}\tau_{h}\left(-a^{2}+\left(c_{1} a+c_{2}\right)\left(1-\exp \left(-\frac{u_{f}(t)}{\bar{u}}\right)\right)\right) & \text { in phases G1 and D } \\ 0 & \text { in phase SM }\end{array}\right.$

where $\tau_{h}, c_{1}, c_{2}$ and $\bar{u}$ are real positive constants. In phases $\mathrm{G} 1$ and $\mathrm{D}$, the cell maturity is modulated by the control term $u_{f}(t)$, and the expression of $h_{f}\left(a, \gamma, u_{f}(t)\right)$ is derived from a reduced model of FSH signaling in granulosa cells (Clément et al., 2001, Am J Physiol Endocrinol Metab 281, E35-53). In phase SM, the cell maturity remains unchanged since cells are committed to complete the cell cycle division after the G1/S checkpoint. Depending on the combination of the values of $\gamma$ and $u_{f}(t), h_{f}\left(a, \gamma, u_{f}(t)\right)$ can be either positive (general case in phase G1) or negative (for relatively high value of $\gamma$ compared to $u_{f}(t)$ in phase D).

\section{3- Cell loss through apoptosis $\lambda(a, \gamma, U(t))$}

$\lambda(a, \gamma, U(t))=\left\{\begin{array}{lr}\kappa \exp \left(-\left(\frac{\gamma-\gamma_{s}}{\tilde{y}}\right)^{2}\right) \times \frac{U_{\max }-U(t)}{U_{\max }} & \text { in phases G1 and D } \\ 0 & \text { in phase SM }\end{array}\right.$

where $\gamma_{s}$ is the maturity threshold for cell cycle exit, $U_{\max }$ is the maximal plasma FSH level, $\kappa, \gamma_{s}$ and $\tilde{y}$ are real positive constants. The term on the left of the multiplication sign describes the intrinsic cell vulnerability as a Gaussian distribution centered on $\gamma_{s}$. The term on the right of the multiplication sign penalizes the follicle when the control term $U(t)$ is low relative to $U_{\text {max }}$. 


\section{4- Global control $U(t)$}

$U(t)=U_{\min }+\frac{U_{\max }-U_{\min }}{1+\exp \left(c(M(t)-m)^{\delta}\right)}$

where $U(t)$ is expressed as a sigmoid function of the ovarian maturity $M(t)$ (the sum of all individual follicular maturities), $U_{\max }$ is the maximal plasma FSH level and $U_{\min }$ the lower bound, $c, \delta$ and $m$ are real positive constants fixing the coordinates of the inflexion point. This function describes the endocrine feedback exerted by the ovaries (through inhibin and estradiol secretion) onto the pituitary gland which secretes FSH.

\section{5- Local control variable $u_{f}(t)$}

$$
u_{f}(t)=\left(b_{1}+\frac{1-b_{1}}{1+\exp \left(-b_{2}\left(m_{f}^{1}(t)-b_{3}\right)\right)}\right) U(t), \text { for } f=1, \ldots, F
$$

where $m_{f}^{1}(t)$ is the follicular maturity of follicle $f$ of the cohort, $b_{1}, b_{2}$ and $b_{3}$ are real positive constants. For each follicle, the local control $u_{f}(t)$ is proportional to the global control $U(t)$ and expressed as an increasing function of the follicular maturity $m_{f}^{1}(t)$. 


\section{Appendix C: Illustrations of cell changes with time during follicular development}

Contents of the Movie entitled "Film2b.avi": Follicular morphogenesis. This movie is an example of animated outputs obtained by numerical simulation of the spatio-temporal model dedicated to the study of follicular morphogenesis (Clément et al., 13, Multiscale Model Simul 11, 719-746). The oocyte (big yellow cell) enlarges gradually, surrounded by proliferating granulosa cells (green cells) which can move to neighboring places when the overcrowding in their birth area is too high.

Contents of the Movie entitled "Gmovie_fol0.mov": Evolution of the cell density within a single follicle during terminal follicular development. This movie is an example of animated and comprehensive outputs obtained by numerical simulation of the model dedicated to the study of terminal follicular development.

The simulation output corresponds to a simplified version of the model with an open loop (when replacing the time-varying feedback value of $U(\mathrm{t})$ by a constant value $U=U$ max), timedependent control and a constant in time aging velocity, equal to 0.5 in phase G1 and to 1 in phase SM. Each snapshot shows the distribution of cells within the spatial domain of a single follicle. The color scale remains the same all along the simulation. The horizontal axis corresponds to the cell age, the vertical axis to the cell maturity. Five successive cell cycles are materialized with grey vertical lines in the bottom part of the domain, while three horizontal lines delimitate the different maturity thresholds: cell cycle exit, entry into, and exit from the apoptosis zone. The initial cell distribution is exponential in age and uniform in maturity, and the total cell number is normalized to one. The cells move towards the right and top of the domain. Whenever they reach the end of the cell cycle they undergo mitosis; the density is doubled when passing through the SM/G1 interface. The effect of the mitosisinduced discontinuity is clearly visible as a color contrast. There is also a discontinuity induced by the difference in the velocity according to the cell phase, that arises at the interface between phase G1 and SM (at half the cell cycle). The cell maturity increases only during phase G1; the vertical velocity is 0 during phase SM, where the cells move horizontally, which participates in the progressive distortion of the cloud. At time $t=0.8$, some cells have undergone mitosis and spread over the second cycle, while a small number of cells are exiting the first cell cycle. At time $t=1.8$, the density is splitting into disconnected regions; some of the cells have exited the proliferation sub-domain and entered phase $\mathrm{D}$, while a small number of them have already escaped from the apoptosis zone. At time $\mathrm{t}=2.8$, three cell clouds (corresponding to cell entry into phase D from three successive cycles) have exited the proliferation sub-domain. At time $t=7.5$, the density has almost completely entered phase $D$ of the domain. At time $t=7.9$ the density has escaped from the apoptosis zone. At larger times the density concentrates in maturity as the average maturity approaches an asymptotic value whose value is fixed by the local control. 